\title{
Factors Affecting Livelihood Re-Establishment of Climate Change Induced Transboundary Displaced Persons
}

\author{
Mikiyasu Nakayama ${ }^{1}$, Nagisa Yoshioka ${ }^{1}$, Hirotaka Fujibayashi ${ }^{1} \&$ Carl Bruch $^{2}$ \\ ${ }^{1}$ Graduate School of Frontier Sciences, The University of Tokyo, Japan \\ ${ }^{2}$ Environmental Law Institute, Washington, DC, U.S.A. \\ Correspondence: Mikiyasu Nakayama, Graduate School of Frontier Sciences, The University of Tokyo, 5-1-5 \\ Kashiwano-ha, Kashiwa, Chiba 277-8563, Japan.
}

Received: July 18, 2016

doi:10.11114/ijsss.v4i9.1744
Accepted: July 29, $2016 \quad$ Available online: August 1, 2016

URL: http://dx.doi.org/10.11114/ijsss.v4i9.1744

\begin{abstract}
Climate Change Induced Transboundary Displaced Persons (CCITDPs) are people who are forced to leave their own country permanently because of adverse effects of climate change such as submergence of homeland by sealevel rise. The type of displacement anticipated by climate change implications is analogous to forced displacement resulting from war, conflict within a country, development projects, industrial accidents, and natural disasters. This study aims to identify the unique aspects of CCITDPs. We developed suggestions regarding how CCITDPs may re-establish their livelihoods by themselves after relocation. People displaced by slow-onset sea-level rise have as many as two to three decades to plan for resettlement, which may let them prepare well for livelihood re-establishment after resettlement. Relocation of CCITDPs may take a few decades; therefore, CCITDPs may learn from those pioneers who moved to a new country first what their possible destination is like. Lack of a responsible body for climate change and the subsequent paucity of funds for relocating CCITDPs is a unique and major difficulty for CCITDPs. Some CCITDPs may view their forced migration as emancipation from conventional thought and old customs, or as a chance to secure a new job. It is desirable to show CCITDPs that their inevitable relocation may be an opportunity rather than a miserable fate.
\end{abstract}

Keywords: climate change, livelihood re-establishment, migration, transboundary environmentally displaced persone

\section{Introduction}

\subsection{Emergence of the concept of Transboundary Environmentally Displaced Persons}

The concept of Climate Change Induced Transboundary Displaced Persons (CCITDPs) stems from articles that appeared in the mid-1980s to the early 1990s. El-Hinnawi (1985), Jacobson (1988), and Myers (1993; 1995) were foundational in linking environmental degradation to human migration. El-Hinnawi (1985) defines "environmental refugees" as "those people who have been forced to leave their traditional habitat, temporarily or permanently, because of a marked environmental disruption (natural and/or triggered by people) that jeopardized their existence and/or seriously affected the quality of their life." (p. 4). The effects of environmental distortions, including ones by climate change, play into other socio-political dynamics that displace populations, e.g., war, internal conflict within a country, loss of livelihoods.

Since El-Hinnawi's definition of environmental refugees, academics and campaigners have proposed a variety of terms to describe CCITDPs, including environmental refugees, climate-change induced migrants, forced migrants by climate-change and environmentally displaced persons (EDPs). There are various disputes around whether or not "environmental refugees" really exist and which term should be used to denote people who have been displaced by climate-related and other environmental factors. Lonergan (1998) considered it difficult to isolate environmental factors from others, such as social, economic, political, or institutional factors, and suggested that at the root of what often appears to be environmentally determined migration are actually developmental disparities between developed and developing worlds. Still, Lonergan's study defined CCITDPs as suggested by El-Hinnawi (1985). This study mainly addresses those in small island developing states (SIDS) who would need to relocate to another nation once their home country had been submerged by rising sea levels (which is unique to the displaced by climate change implications), they suffer from too many disasters (too costly to rebuild) or salination of freshwater sources. SIDS are supposed to be 
impacted by climate change earlier than other (mostly non-island) states. SIDS therefore need to develop strategies for adaption. Migration from SIDS to other nations "increasingly is seen as part of adaptation rather than a failure to adapt" (Betzold, 2015; p481).

The preliminary estimates by Myers (1997) indicated that the total number of people at risk due to sea-level rise could be 73 million in China, 26 million in Bangladesh, 20 million in India, 12 million in Egypt and 31 million elsewhere, totaling approximately 162 million people worldwide. According to Nicholls et al. (2011), most threatened people are concentrated in three regions in Asia: East, Southeast, and South Asia. Given a 0.5 to $2 \mathrm{~m}$ rise in sea levels, a total of 53 to 125 million people are estimated to be displaced over the next century in these three regions alone. In the three small-island regions (the Caribbean, the Indian Ocean, and the Pacific Ocean), 1.2 to 2.2 million people are estimated to be displaced over the next century, with all three small-island regions contributing significantly to the total number of CCITDPs.

As for the number of forced migrants as a result of environmental degradation, Stern (2007) suggested that by 2050 there would be 200 million people affected by adverse climate events that could induce migration, while Christian Aid (2007) predicted that up to one billion people could be displaced due to environmental causes by 2050. The Office of the United Nations High Commissioner for Refugees (2012) stated that environmentally induced migration and displacement could take on unprecedented dimensions, with predictions about the potential scale of such movements ranged from 25 million to one billion by 2050. Despite of the magnitude of anticipated displaced, the way they may re-establish their livelihood after relocation has not been extensively studied.

The majority of these people may relocate within their home countries, while some of them may need to relocate across national borders; these forced migrants are categorized by some as climate change refugees (Docherty \& Giannini, 2009) and by others using alternative terminology. There are various reasons for the terminological variation. As Longeran noted, it is often difficult, if not impossible, to separate environmental factors from other factors. Moreover, aside from those people who will eventually have to move due to sea level rise, it will be difficult to determine whether a particular individual is affected by climate change or simply by weather or climate (trying to isolate the effects of climate change). From a political and legal perspective, humanitarian agencies have resisted referring to people displaced by climate change implications as "refugees, both because there is the question of persecution (and intent) that is a core consideration in granting refugee status and in the fact that if recognized climate refugees could dwarf the number of more conventional refugees at a time when there are already profound shortfalls in assistance to refugees. It should also be noted that there is a legal distinction between refugees and asylum seekers. Due to the terminological difficulties, this article uses the term "CCITDP." Addressing CCITDPs is one of the major challenges in adapting to climate change, and to maintaining international peace and security.

\subsection{Appling Past Experiences to Livelihood Re-Establishment of CCITDPs}

As the Asian Development Bank (2012) suggested, in situ adaptation and resilience-building mechanisms should be the most common response to climate change, and most of the adaptation mechanisms currently being planned aim to keep people in place and promote an alternative to migration. The ambassadors from the island countries in the Pacific interviewed by McNamara and Gibson (2009) insisted that focusing on migration as a strategy for adaptation instead of mitigation represents the globally irresponsible vision for the future. In this context, resettlement should be regarded as the last resort among possible measures for adaptation, although it is inevitable in some cases, such as the loss of habitable land in SIDS due to rising sea levels. The emergence of CCITDPs who migrate from their own countries to other nations seems inevitable in some SIDS, in which intra-nation displacement may not be practiced.

The type of displacement to be caused by adverse effects of climate change is analogous to the forced displacements which took place in the past as a result of development projects (although those displacements were almost universally intra-national), as the Asian Development Bank (2012) pointed out. In addition, resettlement due to climate change has some resemblance to involuntary migration or forced migration (in which people are obligd to leave home and relocate to another place) due to war, conflict within a country, industrial accidents, and natural disasters. It implies that the ways and means that are required to enable CCITDPs to reestablish their livelihoods by themselves after relocating may be identified by scrutinizing past experiences in efforts by resettlers to rebuild livelihoods following forced displacement.

\subsection{Objectives of this Study}

This study aims to identify the aspects unique to CCITDPs' livelihood re-establishment in comparison with refugees and internally displaced persons who are forced to leave their homes, either temporarily or permanently, by causes other than those associated with climate or climate change, as well as to identify the similarities between CCITDPs and migrants by other causes. Based on these identified similarities and differences, we developed suggestions regarding how past experiences should be applied to CCITDPs to enable them to re-establish their livelihoods by themselves after relocating. We placed due emphasis on those CCITDPs in Pacific-region SIDS in elaborating suggestions for smooth 
livelihood re-establishment after relocation.

\section{Method}

While nobody has been officially recognized as a climate-chage refugee yet ("New Zealand deports," 2015), a great number of people in the world have been obliged to relocate due to various reasons not related to climate change. Table 1 summarizes the issues related to these various types of forced migrants, including climate-chage refugees:

1) WHY: Why do they have to relocate?

2) WHAT: What kind of 'safety' are they seeking? What is the nature of their migration?

3) WHEN: When does their movement start? When is their departure from their home country over?

4) WHO: Who relocates first?

5) WHERE: Where do they head first?

6) HOW: How is their cost borne? How are they protected by existing legal frameworks?

This table was populated mostly by referring to previous studies by the authors Nakayama (1998); Nakayama, Yoshida, and Gunawan (2000); Fujikura and Nakayama (2002); Karimi et al. (2005); Souksavath and Nakayama (2013); Nakayama and Fujikura (2014); and Weinthal, Troell, and Nakayama (2014). Martin (2009, p15) identified the following four paths to forced migration due to climate change implications:

(a) "intensification of natural disasters", such as hurricanes and cyclones, that destroy housing and livelihoods and require people to relocate for shorter or longer periods;

(b) "increased warming and drought that affects agricultural production, diminishing people's livelihoods and access to clean water";

(c) "rising sea levels that render coastal areas uninhabitable"; and

(d) "competition over natural resources that may lead to conflict, which, in turn, precipitates displacement".

This study targets the first three types of migration, for the last type — conflict—presumably would be covered by the "war" or "non-international armed conflict" category.

The following four reasons other than climate change implications for involuntary migration were considered in developing the table: a well-founded fear of persecution (e.g., armed conflict, persecution for reasons prescribed in refugee law); development projects (e.g., infrastructure construction); industrial accidents (e.g., pollution, nuclear accident); and geophysical events (e.g., earthquake, volcanic eruption). As for CCITDPs, three reasons for involuntary migration were considered: sudden onset events (e.g., typhoon, flood, landslide); environmental degradation and/or slow onset events (e.g., drought, desertification, land erosion); and sea-level rise.

The Table 1 highlights features unique to CCITDPs, for such features may make the re-establishment of CCITDP's livelihoods significantly different from other forced migrants. At the same time, we also identified similarities between CCITDPs and other involuntary migrants in order to determine how past experiences in effectively rehabilitating of migrants' livelihoods may be applied to improve the livelihood re-establishment of CCITDPs. In the column of "What kind of 'safety' are they seeking for?" in Table 1, physical safety represents prevention of life-thretening danger such as drowning by tsunami, material safety implies securing assets such as lands and houses, and legal dafety means securing legal protection such as maintaining nationality or (in some particular cases) refugee recognition. 
Table 1. Factors affecting forced displacement due to sdverse effects of climate change and due to causes other than climate change implications

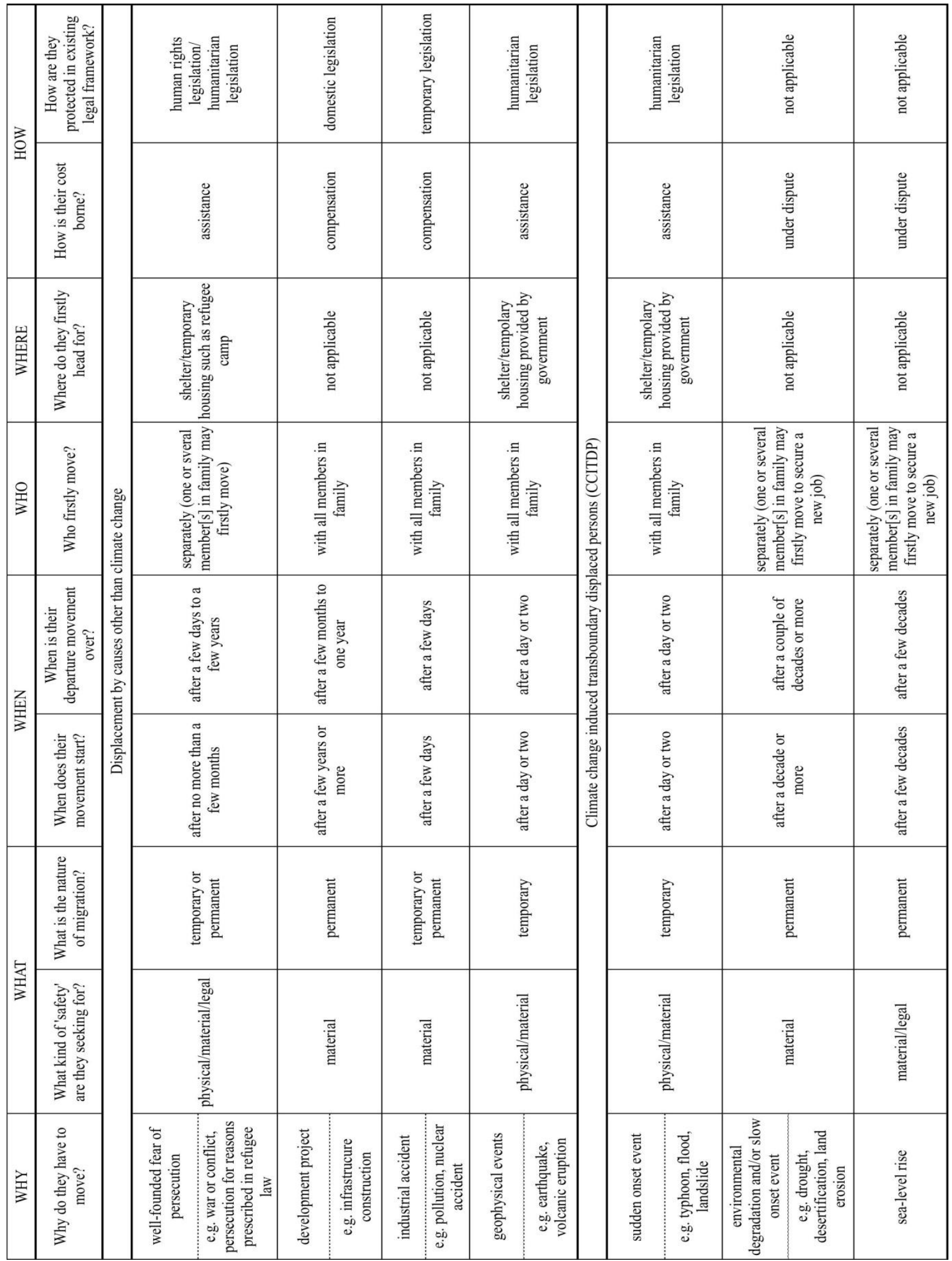




\section{Results}

Table 1 reveals some features unique to CCITDPs, as elaborated below, as well as similarities between CCITDPs and other involuntary migrants. The findings are summarized as follows.

\subsection{Long Time to Plan for Resettlement}

CCITDPs displaced by slow-onset sea-level rise are unique in that they have a long time, as much as a few decades in many cases, to plan for resettlement, which is not the case for sudden-onset events such as natural disasters. CCITDPs by environmental degradation and/or slow-onset events (e.g. drought, desertification, land erosion) may also have a long time to plan for resettlement. Such a long planning period is never found in forced migration by other causes. Refugees due to a well-founded fear of persecution (e.g., armed conflict) may have no more than a few months to decide whether to evacuate from their homes, and evacuees due to geophysical events (e.g., earthquakes, volcanic eruptions) may have a day or two at best to decide whether to leave home. Forced migrants due to development projects (e.g. infrastructure construction) may have as long as several years or more to plan, but they would rarely have more than a decade after establishment of the resettlement plan.

A long period of time to plan may allow CCITDPs to prepare well for livelihood re-establishment after their resettlement. Vocational training may be provided for them in case they need to change jobs after relocating, and they may also have sufficient time to visit several possible destinations to decide where they want to live, provided the necessary funds are made available by some party.

Still, the authors do not intend to discount the impotance of addressing the sudden-onset evens. A striking feature of climate change is the increasing frequency and intensity of natural disasters, which may increase the proportion of displaced due to sudden-onset climate change effects versus those displaced by slow onset events.

\subsection{Long Duration between Relocation of First and Last CCITDPs}

Another aspect of CCITDPs related to sea-level rise, environmental degradation, and/or other slow-onset events is the long duration between the relocations of the first and last CCITDPs, which may also take as long as a few decades. Such a long duration between the first and last migrants is dissimilar to the period for most other involuntary migrants, as in many cases, e.g. by geophysical events and industrial accidents, everyone must evacuate in the space of a few days. But CCITDPs may be able to learn from those pioneers who moved to a new country first what it is like, which could mitigate their anxiety about their livelihoods in their planned destination. For the host country, accepting refugees gradually, ideally over a few decades, may significantly decrease possible tension and conflict between refugees and those already resident in the host country.

This long relocation process blurs the line between forced and voluntary migration. According to Richmond and Valtonen (1994), gradual environmental degradation may initially cause proactive migration, later to be followed by reactive movements. The former is more of a voluntary resettlement than a forced relocation. For CCITDPs of rising sea levels who leave their homelands first, their lives may not be threatened and they may be regarded as voluntary migrants. On the other hand, the last CCITDPs of rising sea levels are forced to evacuate for the sake of their own and their families' lives.

\subsection{Lack of a Mechanism to Cover the Cost of Relocation}

Yet another feature unique to CCITDPs of slow-onset events is the lack of an agreed-upon mechanism to cover the cost of their relocation. To the extent they are covered (and often, they are only partially covered), the costs to meet the needs of refugees of war or conflict are covered by donor countries, nongovernmental organizations, and international organizations such as the United Nations High Commissioner for Refugees, the International Organization for Migration, and the International Federation of Red Cross and Red Crescent Societies. The cost for evacuees from industrial accidents, such as the internally displaced persons from Fukushima Prefecture of Japan due to the explosion of the Fukushima Daiichi Nuclear Power Plant in 2011, should be covered by a party that is found to be responsible for the accident. Similarly, forced resettlement due to a dam construction project should be funded by the owner of the dam. Currently, the costs to deal with evacuees of natural disasters are usually met by local governments, central governments, or with the assistance of an international organization.

Piguet, Pécoud, and de Guchteneire (2011) pointed out that slow-onset events, such as sea-level rise, draw limited policy attention. Glantz, Ye, and Ge (2001) also warned that creeping environment problems, which represent the changes that are imperceptible from one day to the next, tend to be ignored by governments in the short term. In contrast to responses to slow-onset disasters, Piguet, Pécoud, and de Guchteneire (2011) suggested that governments and policy-makers react immediately to sudden and devastating natural disasters, such as tsunamis or hurricanes.

Moberg (2008) reviewed the existing legal framework related to refugees or displaced persons, and proposed to create 
an environmentally-based immigration visa (EBIV) program in order to protect CCITDPs. In this proposed program, countries - especially wealthier countries - would share the burden of accepting CCITDPs. Moberg also proposed to allocate the number of immigration visas that each country should extend in proportion to the percentage of greenhouse gas emissions that country produces. Her suggestions are, however, not yet in practice, and the question of how the costs should be borne to relocate CCITDPs of environmental degradation and/or slow-onset events and sea-level rise is disputed.

It seems likely that the assistance provided to CCITDPs would not be as generous as the compensation given to involuntary migrants as a result of industrial accidents or development projects; at best, it may be similar to the assistance that is presently given to refugees of armed conflict.

\subsection{Similarities to Other Forced Migration}

CCITDPs resulting from sea-level rise, environmental degradation, and other slow-onset events share a similarity with involuntary migrants due to armed conflict: in many cases, neither group returns to their homes, and they must re-establish their livelihoods in a new country. One or several members of a family may move first to secure a new job in the family's anticipated destination - usually from a temporary accommodation — so that the family can re-establish their livelihood smoothly. Alternatively, if the initial destination does not seem suitable for the family, one or several members of a family may move to another destination. Moving to a short-term destination is unlikely for CCITDPs of slow-onset events, as is the case with development project, because CCITDPs of slow-onset events have much longer to plan for relocation than other forced migrants.

CCITDPs resulting from sudden-onset events (e.g., typhoons, floods, landslides) have few differences from other evacuees of natural disasters in terms of the factors discussed in Table 1. Still, evacuees of other natural disasters are, in most cases, assumed to return home, while CCITDPs may decide not to return, as they would face an increasing probability of suffering from severe natural disasters - an increase that is due to climate change. Continuing their livelihood is therefore more difficult for CCITDPs than evacuees of other natural disasters.

\section{Discussion}

It may be misleading to regard CCITDPs as people who are doomed and have no hope. Hartmann (2010) warned that the decision to relocate or not entails many more factors than climate change implications alone. CCITDPs have a long time to think about their future, specifically about where to move and what to do after relocation, which may allow sufficient time for them to experience a personal paradigm shift. Leaving their homeland involuntarily may cause CCITDPs to feel a sense of loss in terms of their cultural and societal ties; however, some of them may view their forced migration as an opportunity to emancipate themselves from conventional thought, value judgment, and old customs. Some of the internally displaced persons who were forced to evacuate following the Fukushima Daiichi Nuclear Power Plant disaster expressed such a sense of emancipation during interviews with authors.

This implies that CCITDPs may not necessarily regard their forced relocation as a miserable fate, and that some of them may even consider it an opportunity for a new and different lifestyle. In developing measures to address CCITDPs, this possibility should be given due consideration in order not to misguide CCITDPs in planning their new livelihoods after migration. Moving to another country en masse by developing an area specifically for CCITDPs from a particular country may feel comfortable to those who value their culture and language. On the other hand, living in such a place may be regarded as servitude to old customs and conventions by those who are keen to move on from their past, and it may impede long-term integration of the displaced population into the new host country.

CCITDPs may see their relocation as a chance to secure a new job. McAdam and Loughry (2009) suggested that a lack of employment and development opportunities was, at the time, one of the major drivers of emigration in Kiribati and Tuvalu. For those who are starving for employment opportunities, becoming CCITDPs may be regarded as a chance to seek jobs in another country with more job opportunities. It should also be noted that the effects of climate change may have some positive benefits, e.g., increased rainfall could boost harvests in the destination of CCITDPs, while these possible positive aspects tend to be inadequately addressed. Changes in temperature could also improve crop growth or open up possible cash crops where they previously did not exist, which may lead to more employment opportunities in farming sector for CCITDPs after relocation.

The possibility of such a possible mindset among CCITDPs should be taken into consideration when developing resettlement packages, for some of them may feel more comfortable being regarded as proactive opportunity-seekers or job-seekers, rather than reactive victims and miserable refugees. Such a proactive mindset was common among involuntary migrants in Japan due to dam construction projects (Fujikura \& Nakayama, 2015). In those cases, the migrants found little hope for the future in their original homes and they were keen to seek jobs in cities or suburbs. Some residents in SIDS who are likely to be CCITDPs in the foreseeable future may also find few job opportunities in 
their home countries, as there may be impediments to major investment in places that might be underwater or affected by increasingly devastating storms in the foreseeable future.

In the "How is their cost borne?" column of Table 1, the causes of "environmental degradation and/or slow onset event" and "sea-level rise" are described as "under dispute," while other involuntary migrants are supported either by compensation or assistance. This implies that the method to cover the cost of relocating CCITDPs, either by compensation or assistance, is still disputed by scholars. In other words, the international community has not reached a consensus regarding the question of who is responsible for climate change; this issue has been debated since the onset of the concept of climate change, and no clear-cut answer has yet been found.

Therefore, another possibility should be considered to overcome this impasse. One successful endeavor to overcome the deadlock in covering the cost of relocating CCITDPs is the Green Climate Fund (GCF), one of the climate funds established in 2010 under the United Nations Framework Convention on Climate Change, which succeeded in raising funds for climate change adaptation without needing to answer the question of who bears the responsibility of climate change. Klein and Möhner (2011) pointed out that it may not be feasible for the GCF to prioritize any particular group of countries. GCF is thus not meant for compensation, which is usually earmarked for particular losses or damages. Some developed countries have provided financing to aid in migration (Goodenough, 2016), which may sometimes be viewed as a strategy to avoid having to accept immigrants from other countries (Warren, in press). If this logic is applicable to the GCF, contributions from developed countries to the GCF may be regarded not as compensation for causing climate change, but rather as a means of avoiding accepting immigrants. In other words, the GCF itself may be regarded not as compensation for the cause of climate change, but as assistance for the consequences of climate change. The very nature of the GCF has been, and should be, kept purposely ambiguous, so that developed countries may contribute to it with peace of mind.

During the 2015 Paris Climate Conference (COP21) in December 2015, some developing countries suggested creating a climate-change induced displacement coordination facility to address forced internal and cross-border displacement as a result of climate change. One of the aims of the proposed climate-change displacement coordination facility was to undertakes compensation measuresw for persons displaced by climate change (Wentz \& Burger, 2015). However, the final adopted text of the agreement contained no explicit reference to such a facility. The reason the creation of a climate-change displacement coordination facility was dropped from the agreement was because Australia opposed the creation of a coordination facility (Milman, 2015).

It is reasonable to assume that the concept of compensation in the draft agreement intimidated some developed countries, for the proposal by the COP President clearly states that "Article 8 of the Agreement does not involve or provide a basis for any liability or compensation" (UNFCCC, 2015, p. 8). Despite of the difficulty of reaching a global consensus in 2015 , moving forward a climate-change displacement coordination facility should be seriously considered in the efforts to break through the impasse in financing migration related to climate change on a local or regional level. Warren (in press) suggested that the creation of a climate-change displacement coordination facility would support regional agreements that require acceptance of CCITDPs and use the GCF to fill the funding gap.

It is desirable, and possible, to encourage CCITDPs to view their inevitable relocation as an opportunity rather than a miserable fate. Appropriate funding mechanism should also be established for the sake of smooth re-establishment of their livelihood. We hope that this study depicted at least a part of the bigger picture toward this end.

\section{Acknowledgements}

This study was supported by KAKENHI (16H03320) and the University of Tokyo Graduate School of Frontier Sciences.

\section{References}

Arenas, C. (2015). A climate change displacement coordination facility in the Paris draft agreement. Retrieved from http://displacementsolutions.org/wp-content/uploads/2015/11/Climate-change-displacement-coordination-facility.p df

Asian Development Bank. (2012). Addressing climate change and migration in Asia and the Pacific. Mandaluyong City, Philippines: Author.

Betzold, C. (2015). Adapting to climate change in small island developing states. Climatic Change, 133(3), 481-489. http://dx.doi.org/10.1007/s10584-015-1408-0

Christian Aid. (2007). Human tide: The real migration crisis. Retrieved from https://www.christianaid.org.uk/Images/human-tide.pdf

Docherty, B., \& Giannini, T. (2009). Confronting a rising tide: A proposal for a convention on climate change refugees. 
Harvard Environmental Law Review, 33, 349-403.

http://www.law.harvard.edu/students/orgs/elr/vol33_2/Docherty\%20Giannini.pdf

El-Hinnawi, E. (1985). Environmental refugees. Nairobi, Kenya: United Nations Environment Programme.

Fujikura, R., \& Nakayama, M. (2002). Post hoc review of involuntary resettlement issues in two power generation projects. Development in Practice, 12(2), 208-212.

Fujikura, R., \& Nakayama, M. (Eds.). (2015). Resettlement policy in large development projects. Abingdon, UK: Routledge.

Glantz, M. H., Ye, Q., \& Ge, Q. (2001). China's western region development strategy and the urgent need to address creeping environmental problems. Arid Lands Newsletter, 49(3), 612-616.

Goodenough, P. (2016, March 14). Days after \$500 million US contribution, U.N. Green Climate Fund increases staff by $150 \%$. CNS News.

http://www.cnsnews.com/news/article/patrick-goodenough/days-after-500000-us-contribution-un-green-climate-fu nd-increases

Hartmann, B. (2010). Rethinking climate refugees and climate conflict: Rhetoric, reality and the politics of policy discourse. Journal of International Development, 22(2), 233-246. http://dx.doi.org/10.1002/jid.1676

Jacobson, J. L. (1988). Environmental refugees; a yardstick of habitability. In Worldwatch Paper (No. 86). Worldwatch Institute. ISBN 0-916468-87-9.

Karimi, S., Nakayama, M., Fujikura, R., Katsurai, T., Iwata, M., Mori, T., \& Mizutani, K. (2005). Post-project review on a resettlement programme of the Kotapanjang Dam Project in Indonesia. International Journal of Water Resources Development, 21(2), 371-384. http://dx.doi.org/10.1080/07900620500038147

Klein, R. J., \& Möhner, A. (2011). The political dimension of vulnerability: Implications for the Green Climate Fund. IDS Bulletin, 42(3), 15-22. http://dx.doi.org/10.1111/j.1759-5436.2011.00218.x

Lonergan, S. (1998). The role of environmental degradation in population displacement. Environmental Change and Security Project report, 4(4), 5-15.

Martin, S. F. (2009). Migration, Environment and Climate Change: Assessing the Evidence, Geneva, International Organization for Migration, 353-384.

McAdam, J., \& Loughry, M. (2009, June 30). We aren't refugees. Inside Story, 29. Retrieved from http://insidestory.org.au/we-arent-refugees

McNamara, K. E., \& Gibson, C. (2009). 'We do not want to leave our land': Pacific ambassadors at the United Nations resist the category of 'climate refugees'. Geoforum, 40(3), 475-483.

http://dx.doi.org/10.1016/j.geoforum.2009.03.006

Milman, O. (2015, October 7). UN drops plan to help move climate-change affected people. The Guardian. Retrieved from

https://www.theguardian.com/environment/2015/oct/07/un-drops-plan-to-create-group-to-relocate-climate-changeaffected-people

Moberg, K. K. (2008). Extending refugee definitions to cover environmentally displaced persons displaces necessary protection. Iowa L. Rev., 94, 1107.

Myers, N. (1993). Environmental refugees in a globally warmed world. BioScience, 43(11), 752-761. http://dx.doi.org/10.2307/1312319

Myers, N. (1995). Environmental unknowns. Science, 269(5222), 358-360.

Myers, N. (1997). Environmental refugees. Population and Environment, 19(2), 167-182.

Nakayama, M. (1998). Post-project review of environmental impact assessment for Saguling Dam for involuntary resettlement. International Journal of Water Resources Development, 14(2), 217-229. http://dx.doi.org/10.1080/07900629849411

Nakayama, M., \& Fujikura, R. (Eds.). (2014). Restoring communities resettled after dam construction in Asia. Abingdon, UK: Routledge.

Nakayama, M., Yoshida, T., \& Gunawan, B. (2000). Improvement of compensation system for involuntary resettlers of dam construction projects. Water Resources Journal, 206, 80-93.

New Zealand deports climate change asylum seeker to Kiribati. (2015, September 24). BBC. Retrieved from 
http://www.bbc.com/news/world-asia-34344513

Nicholls, R. J., Marinova, N., Lowe, J. A., Brown, S., Vellinga, P., de Gusmão, D., ... Tol, R. S. (2011). Sea-level rise and its possible impacts given a 'beyond $4^{\circ} \mathrm{C}$ world' in the twenty-first century. Philosophical Transactions. Series A, Mathematical, physical, and engineering sciences, 369(1934), 161-181. http://dx.doi.org/10.1098/rsta.2010.0291

The Office of the United Nations High Commissioner for Refugees. (2012). The state of the world's refugees: In search of solidarity. Retrieved from http://www.unhcr.org/4fc5ceca9.pdf

Piguet, E., Pécoud, A., \& De-Guchteneire, P. (2011). Migration and climate change: An overview. Refugee Survey Quarterly, 30(3), 1-23. http://dx.doi.org/10.1093/rsq/hdr006

Richmond, A. H., \& Valtonen, K. (1994). Global apartheid: Refugees, racism, and the new world order. Refuge: Canada's Journal on Refugees, 14(6), 25-26.

Souksavath, B., \& Nakayama, M. (2013). Reconstruction of the livelihood of resettlers from the Nam Theun 2 hydropower project in Laos. International Journal of Water Resources Development, 29(1), 71-86.

Stern, N. H. (2007). The economics of climate change: The Stern review. Cambridge, England: Cambridge University Press.

United Nations Framework Convention on Climate Change. (2015). (FCCC/CP/2015/L.9/Rev.1). Retrieved from https://unfccc.int/resource/docs/2015/cop21/eng/109r01.pdf

Warren, P. (in press). Evaluating the 'climate change displacement coordination facility': How the UNFCCC can address forced migration after Paris COP21. Columbia Law Review. Retrieved from http://papers.ssrn.com/sol3/papers.cfm?abstract_id=2760131

Weinthal, E., Troell, J. J., \& Nakayama, M. (Eds.). (2014). Water and post-conflict peacebuilding. Abingdon, UK: Routledge.

Wentz, J. A., \& Burger, M. (2015). Designing a climate change displacement coordination facility: Key issues for COP 21. New York, NY: Sabin Center for Climate Change Law, Columbia Law School.

\section{(cc) $\mathrm{BY}$}

This work is licensed under a Creative Commons Attribution 3.0 License. 